Canadian Science Publishing

Applied Physiology, Nutrition, and Metabolism Physiologie appliquée, nutrition et métabolisme

\title{
Myostatin dysfunction impairs force generation in extensor digitorum longus muscle and increases exercise-induced protein efflux from soleus muscle
}

\begin{tabular}{|r|l|}
\hline Journal: & Applied Physiology, Nutrition, and Metabolism \\
\hline Manuscript ID: & apnm-2014-0513.R1 \\
\hline Manuscript Type: & Article \\
\hline Complete List of Authors: & $\begin{array}{l}\text { Baltusnikas, Juozas; Lithuanian Sports University, } \\
\text { Kilikevicius, Audrius; Lithuanian Sports University, } \\
\text { Venckunas, Tomas; Lithuanian Sports University, } \\
\text { Fokin, Andrej; Lithuanian Sports University, } \\
\text { Bünger, Lutz; Scotland's Rural College (SRUC), } \\
\text { Lionikas, Arimantas; University of Aberdeen, } \\
\text { Ratkevicius, Aivaras; University of Aberdeen, School of Medical Sciences; } \\
\text { Lithuanian Sports University, }\end{array}$ \\
\hline Keyword: & muscle damage < muscle \\
\hline
\end{tabular}


1 Myostatin dysfunction impairs force generation in extensor digitorum longus muscle and

2 increases exercise-induced protein efflux from extensor digitorum longus and soleus

4

5 Juozas Baltusnikas ${ }^{1}$, Audrius Kilikevicius ${ }^{1}$, Tomas Venckunas ${ }^{1}$, Andrej Fokin ${ }^{1}$, Lutz

6 Bünger $^{3}$, Arimantas Lionikas ${ }^{2}$, Aivaras Ratkevicius ${ }^{1,2}$.

7

$8 \quad{ }^{1}$ Institute of Sports Sciences and Innovation, Lithuanian Sports University, Kaunas, Lithuania

$9{ }^{2}$ School of Medical Sciences, College of Life Sciences and Medicine, University of

10 Aberdeen, Aberdeen, Scotland, UK

$11{ }^{3}$ Scotland's Rural College (SRUC), Edinburgh, UK

13 Correspondence to:

14 Juozas Baltušnikas, MSc

15 Institute of Sports Sciences and Innovation, Lithuanian Sports University,

16 Sporto 6, LT-44221, Kaunas, Lithuania

17 Phone: +370671 00819; Fax:+370 37204 515, E-mail: juozas.baltusnikas@1su.lt

19 E-mails:

20 Kilikevicius Audrius: audrius.kilikevicius@1su.lt

21 Venckunas Tomas: tomas.venckunas@1su.lt

22 Fokin Andrej: fokinandrej@yahoo.com

23 Lutz.Bunger@sruc.ac.uk

24 Lionikas Arimantas: a.lionikas@abdn.ac.uk

25 Ratkevicius Aivaras: a.ratkevicius@abdn.ac.uk 


\section{ABSTRACT}

27 Myostatin dysfunction promotes muscle hypertrophy which can complicate assessment of 28 muscle properties. We examined force generating capacity and creatine kinase (CK) efflux 29 from skeletal muscles of young mice before they reach adult body and muscle size. Isolated 30 soleus (SOL) and extensor digitorum longus (EDL) muscles of Berlin high (BEH) mice with 31 dysfunctional myostatin, i.e. homozygous for inactivating myostatin mutation, and with a 32 wild type myostatin $(\mathrm{BEH}+/+)$ were studied. The muscles of $\mathrm{BEH}$ mice showed faster $(\mathrm{P}<$ 33 0.01) twitch and tetanus contraction times compared to $\mathrm{BEH}+/+$ mice, but only $\mathrm{EDL}$ 34 displayed lower $(\mathrm{P}<0.05)$ specific force. SOL and EDL of age matched, but not younger 35 BEH mice showed greater exercise-induced $\mathrm{CK}$ efflux compared to $\mathrm{BEH}+/+$ mice. In 36 summary, myostatin dysfunction leads to impairment in muscle force generating capacity in 37 EDL and increases susceptibility of SOL and EDL to protein loss after exercise.

39 Keywords: lengthening contractions, muscle force, muscle damage, myostatin. 


\section{INTRODUCTION}

42 Skeletal muscles play an important role in health and disease (Wolfe 2006). Unaccustomed exercise and some diseases can lead to injury and efflux of proteins from the affected muscles (Armstrong 1984). An increase in total plasma CK activity has been used as evidence of muscle damage after exercise in humans (Brancaccio et al. 2007; Skurvydas et al. 2011). However, swelling and infiltration of skeletal muscles by immune cells can occur without signs of structural damage after exercise (Pizza et al. 2002, Yu et al. 2013). It is believed that exercise increases permeability of sarcolemma and can trigger the secondary events associated with actions of immune system (Tidball 1995; McHugh 2003, Yu et al. 2013). Isolated skeletal muscle model permits studying the primary effects of exercise by limiting

51 the complex influence of the immune and hormonal systems (Jackson et al. 1987; Suzuki et al. 1999).

54 Various hormones and growth factors can affect functional properties and susceptibility to 55 damage of the skeletal muscles (Amelink et al. 1990). There has been a considerable interest 56 in effects of myostatin (Smith and Lin 2013). Myostatin knockout is associated with a 57 significant increase in muscle mass due to muscle fiber hypertrophy and hyperplasia 58 (McPherron et al. 1997). Myostatin blockade can improve muscle function in Duchenne 59 muscular dystrophy (Bogdanovich et al. 2002), and has been proposed as a promising 60 treatment strategy against muscle wasting in chronic diseases (Grossmann et al. 2014).

61 However, myostatin dysfunction has also been associated with low specific force of skeletal 62 muscles (Amthor et al. 2007; Matsakas et al. 2010). Interestingly, endurance training can lead 63 to normalization of specific muscle force in myostatin null mice (Matsakas et al. 2012). Food 64 restriction was also associated with an increase in specific muscle force of these mice 65 (Matsakas et al. 2013). Both endurance training and food restriction caused a reduction in 
66 muscle mass, which might improve intramuscular force transmission. Furthermore, myostatin

67 dysfunction is also associated with a shift in muscle fiber composition towards faster contracting fiber types (Amthor et al. 2007). Type 2 muscle fibers characterized by a faster contraction time and are more sensitive to exercise-induced muscle damage than slow contracting type 1 fibers (Macaluso et al. 2012; Chapman et al. 2013). Thus myostatin inhibition may increase susceptibility of skeletal muscles to damage (Mendias et al. 2006).

It appears that myostatin effects are complex, vary between the skeletal muscles and can be further complicated by excessive muscle hypertrophy. The aim of our study was to examine effects of myostatin dysfunction on contractile properties and CK efflux in skeletal muscles of young mice before they reached adult body and muscle size. We have studied extensor digitorum longus (EDL) and soleus (SOL) muscles from Berlin high (BEH) mice with mutant myostatin, known as compact allele, and the wild type myostatin allele $(\mathrm{BEH}+/+)($ Amthor et al. 2007; Lionikas et al. 2013). The $\mathrm{BEH}$ and $\mathrm{BEH}+/+$ mice were matched by muscle mass to minimize the influence of excessive muscle hypertrophy as a possible confounding factor.

\section{MATERIALS AND METHODS}

\section{Animals and experiments}

84 All procedures of this experiment were approved by the Lithuanian State Food and 85 Veterinary Service (Nr. 0223). BEH+/+ females were generated by crossing animals from $86 \mathrm{BEH}$ and Berlin Low (BEL) strains and then repeatedly backcrossing the offspring to BEH 87 using marker assisted selection for the wild type myostatin (Amthor et al. 2007; Lionikas et al. 2013). The data on age, body mass and muscle mass of these animals are presented in Table 1. BEH mice were younger than $\mathrm{BEH}+/+$ mice when matched by the muscle mass of SOL or EDL. The age difference between the strains was particularly significant in case of 
EDL. Thus additional measurements were carried out on EDL of BEH mice of a similar age as $\mathrm{BEH}+/+$ mice. Prior to the in vitro experiments, animals were kept in standard cages (cage dimensions: $267 \times 207 \times 140 \mathrm{~mm}$ ) at $20-22^{\circ} \mathrm{C}$ temperature and $55 \pm 10 \%$ humidity with $12 / 12$ h light/dark cycle. As in our previous studies (Kilikevicius et al. 2013, Lionikas et al. 2013), mice were housed one to three mice per cage, fed standard rodent diet $(58.0 \% \mathrm{kcal}$ from carbohydrates, $28.5 \%$ kcal from protein, $13.5 \%$ kcal from fat; LabDiet 5001, LabDiet, St. Louis, USA) and received tap water ad libitum.

\section{Muscle properties and CK efflux}

All experiments were performed at room temperature $\left(\sim 25^{\circ} \mathrm{C}\right)$. Mice were euthanized by the cervical dislocation. Afterwards, SOL or EDL muscle of the right leg was dissected, freed from tendons, blotted and weighed (Kern, ABS 80-4, Germany). Muscles of the left leg were used for assessment of contractile properties and total muscle CK efflux as described previously (Baltusnikas et al. 2014). The muscles were dissected and placed immediately in the organ bath containing Tyrode solution $(121 \mathrm{mM} \mathrm{NaCl}, 5 \mathrm{mM} \mathrm{KCl}, 0.5 \mathrm{mM} \mathrm{MgCl} 2,1.8$ $\mathrm{mM} \mathrm{CaCl}_{2}, 0.4 \mathrm{mM} \mathrm{NaH}_{2} \mathrm{PO}_{4}, 0.1 \mathrm{mM} \mathrm{NaEDTA}, 24 \mathrm{mM} \mathrm{NaHCO}_{3}, 5.5 \mathrm{mM}$ glucose) which was bubbled with $95 \% \mathrm{O}_{2}$ and $5 \% \mathrm{CO}_{2}$ to attain a $\mathrm{pH}$ of $\sim 7.4$. Muscles were fixed between two platinum plate electrodes of the muscle test system (1200A-LR Muscle Test System, Aurora Scientific Inc., Aurora, Canada). Then the muscle length was increased progressively in steps until peak force was reached in $150-\mathrm{Hz}$ tetani of $0.5-\mathrm{s}$ or 2 -s duration which were induced every $2 \mathrm{~min}$ in EDL or SOL, respectively. Single stimulus was then delivered to assess twitch contraction time and $90 \%$ twitch relaxation time, and this was followed by a measurement of peak tetanic force as well as $90 \%$ contraction and relaxation times. Then muscles were subjected to 100 eccentric contractions at a frequency of $0.1 \mathrm{~Hz}$. During the exercise, muscles were stimulated at $150 \mathrm{~Hz}$ stimulation for $700 \mathrm{~ms}$. During the last $200 \mathrm{~ms}$ of this stimulation a ramp stretch was performed followed by $200 \mathrm{~ms}$ gradual return of the 
116 muscle to the initial length without any stimulation. The amplitude of the stretch was equivalent to 2.5 fiber lengths per second in case of both SOL and EDL muscles (Brooks and Faulkner 1988). After the eccentric exercise muscles were photographed with the length scale in the background for assessment of optimal muscle length $\left(\mathrm{L}_{0}\right)$. Then these muscle as well as muscles from the control experiment without any exercise, were incubated in $2 \mathrm{ml}$ of Tyrode solution for $2 \mathrm{~h}$ at room temperature. $250 \mu \mathrm{l}$ of Tyrode solution was sampled for assessment

122 of CK activity using biochemical analyser (Spotchem ${ }^{\mathrm{TM}}$ EZ SP-4430, Menarini Diagnostics, UK) with the reagent strips (Arkray Factory, Inc., Shiga, Japan).

The physiological cross-sectional areas (pCSA) of SOL and EDL were estimated by dividing muscle weight by the product of fiber length and $1.06 \mathrm{~kg} \mathrm{l}^{-1}$, the density of mammalian skeletal muscle (Brooks and Faulkner 1988). Muscle fiber length was assumed to be equal to $45 \%$ and $70 \%$ of muscle length for EDL and SOL, respectively. Muscles tended to show a slight increase in weight after the experimental protocol involving repetitive exercise. Thus weights of the contralateral muscles were used in these assessments. In a large set of samples $(n=101)$ we dissected both left and right solei of adult mice to immediately measure wet muscle mass; there was no difference (paired t-test $\mathrm{p}=0.953$ ) found in weights of the contralateral muscles.

\section{Statistical analysis}

134 All data analysis was performed using Prism 5.0 software. Data for SOL and EDL were analyzed separately. The two factor analysis of variance (ANOVA) was used to assess effects of experimental intervention (exercise or rest) and mouse strain $(\mathrm{BEH}+/+$ or $\mathrm{BEH})$ on muscle CK efflux. Repeated measures ANOVA was used for the analysis of peak isometric force during eccentric exercise. The post hoc testing was carried out using t-tests with a Bonferroni correction for multiple comparisons. Non parametric Mann-Whitney U test was used in all other cases. All the tests were two-tailed with significance level was set at $\mathrm{P}<0.05$. 


\section{RESULTS}

Data on muscle properties of $\mathrm{BEH}+/+$ and $\mathrm{BEH}$ mice are presented in Table 2. There were no strain differences for SOL muscle. However, strain effects were found in EDL. BEH+/+ mice had a longer $\mathrm{L}_{0}(\mathrm{P}<0.01)$ and a smaller $(\mathrm{P}<0.01)$ pCSA of EDL compared to BEH mice. The older BEH mice showed the greatest pCSA $(\mathrm{P}<0.01)$ of this muscle. In spite of greater pCSA, EDL of young BEH generated less force $(\mathrm{P}<0.05)$ and showed a lower $(\mathrm{P}<0.01)$ specific force compared to $\mathrm{BEH}+/+$. The older $\mathrm{BEH}$ mice had the highest $(\mathrm{P}<0.01)$ peak force for EDL, but their specific force was similar as in young BEH mice and lower $(\mathrm{P}<$ 0.01) compared to $\mathrm{BEH}+/+$ mice.

The contraction speed of a single twitch and tetanus of the muscles from $\mathrm{BEH}+/+$ and $\mathrm{BEH}$ mice are presented in Table 2. For SOL, BEH mice had shorter contraction times in single twitch $(\mathrm{P}<0.01)$ and $150-\mathrm{Hz}$ tetani $(\mathrm{P}<0.01)$ than $\mathrm{BEH}+/+$ mice. Data for the EDL were less consistent than for SOL. BEH mice had longer contraction times $(\mathrm{P}<0.01)$, but shorter $(\mathrm{p}<0.05)$ relaxation times in single twitches compared to $\mathrm{BEH}+/+$ mice. The opposite was true for tetani. Relaxation times were longer $(\mathrm{P}<0.01)$ for $\mathrm{BEH}$ mice compared to $\mathrm{BEH}+/+$. Only older, but not younger BEH mice showed shorter $(\mathrm{p}<0.05)$ contraction times of tetanus than $\mathrm{BEH}+/+$ mice.

Data on peak isometric force for SOL and EDL during repeated isometric-eccentric exercise are shown in Fig. 1. BEH+/+ and young BEH mice showed similar loss $(\mathrm{P}<0.001)$ of peak isometric force for both muscles during the exercise. For EDL, older BEH mice showed a greater $(\mathrm{P}<0.05-0.01)$ decline in isometric force compared to both young $\mathrm{BEH}$ and $\mathrm{BEH}+/+$ 
167

168

mice after initial ten and twenty contractions, respectively. Afterwards, however, the relative decline of peak isometric force was similar in all mice.

Data on the total CK efflux from the muscles of mice are presented in Fig. 2. There were no differences between the strains in muscle CK efflux when measurements were performed at rest, i.e. without prior exercise. After the exercise muscle CK efflux increased $(\mathrm{P}<0.05-0.01)$ and younger $\mathrm{BEH}$ mice showed a greater $(\mathrm{P}<0.05) \mathrm{CK}$ efflux from SOL compared to $\mathrm{BEH}+/+$ mice. There were no differences between these mice for the EDL. However, older BEH mice showed a greater $(\mathrm{P}<0.05) \mathrm{CK}$ efflux from EDL compared to the age-matched $\mathrm{BEH}+/+$ and younger $\mathrm{BEH}$.

\section{DISCUSSION}

The aim of the study was to examine the effects of myostatin dysfunction on the contractile properties and total CK efflux from SOL and EDL muscles at rest and after exercise. The results of the study show that BEH mice with myostatin dysfunction had lower specific force than $\mathrm{BEH}+/+$ mice with the wild type myostatin in the faster contracting EDL, but not in the slower contracting SOL. Furthermore, BEH mice demonstrated greater exercise-induced muscle $\mathrm{CK}$ efflux compared to $\mathrm{BEH}+/+$ when mice of similar age were compared, but not at young age. These results show that effects of myostatin dysfunction vary between skeletal muscles and depend on the age of mice.

Myostatin dysfunction is associated with excessive muscle hypertrophy (McPherron et al. 1997) and reduction in specific muscle force of the fast contracting EDL (Amthor et al. 2007; Mendias et al. 2006). It has been hypothesized that enlargement of muscle fibers might impair force transmission within the skeletal muscles due to an increase in muscle fiber 
190 pennation angles (Amthor et al. 2007). However, muscle fibers of myostatin null mice might 191 also show an intrinsic reduction in force output due to a low content of contractile proteins 192 (Qaisar et al. 2012). We studied skeletal muscles of young mice before they developed

excessive muscularity. This approach minimized confounding effects of muscle hypertrophy. Nevertheless, EDL of BEH mice showed lower specific force compared to $\mathrm{BEH}+/+$ mice in both cases, i.e. when muscles were matched by weight or age. Thus impairment in force generating capacity of EDL muscle in myostatin deficient mice was independent of muscle size, and appears to be due to reduced force output at the level of single muscle fibers (Qaisar et al. 2012). Interestingly, BEH+/+ and BEH mice did not differ in the specific force of SOL muscle. Similar findings on the differences between EDL and SOL muscles have been reported for adult mice (Mendias et al. 2006). Endurance training can improve specific force of skeletal muscles in myostatin null mice (Matsakas et al. 2012). It might be that motor activity helps to maintain specific force of SOL in BEH mice in spite of myostatin deficiency. SOL muscle shows markedly greater involvement in locomotion than other leg muscles which prevail in daily activity of mice including EDL (Roy et al. 1991).

BEH mice showed shorter contraction times in both single twitches and tetani of SOL compared to $\mathrm{BEH}+/+$ mice. This might be associated with a shift in muscle fiber composition towards faster contracting fiber types in SOL muscle of mice with myostatin deficiency compared to the wild type mice (Girgenrath et al. 2005; Amthor et al. 2007; Matsakas et al. 2010). Fast twitch muscle fibers of mice and humans are more susceptible to damage after eccentric exercise than slow twitch muscle fibers (Mendias et al. 2006; Chapman et al. 2013). Indeed, SOL muscle of BEH mice showed greater CK efflux after exercise compared to 214 
215 Effects of myostatin dysfunction were less consistent for EDL than SOL. This might be

216 associated with differences in myostatin effects on fiber type composition of EDL and SOL.

217 Myostatin dysfunction causes a marked increase in content of $2 \mathrm{X}$ and $2 \mathrm{~B}$ fibers at the 218 expense of type 1 fibers in SOL, but induces only a small increase in content of type 2B 219 fibers at the expense of type 2X fibers in EDL (Girgenrath et al. 2005). Age of the studied 220 mice might also be of importance here. $\mathrm{BEH}$ mice of similar age as $\mathrm{BEH}+/+$ mice, but not 221 young BEH mice showed elevated CK efflux from EDL after eccentric exercise compared to $222 \mathrm{BEH}+/+$ mice. A study by Gokhin et al. 2008 demonstrated that contractile force, fiber cross223 sectional area, area of the fibers occupied by the contractile proteins, and percentage of type 224 2B fibers increase rather drastically in mouse tibialis anterior muscle between day 1 and day 22521 after birth. Then the changes between day 21 and day 28 are much more subtle. For 226 instance, area of the fibers occupied by the contractile proteins - the most relevant index in 227 relation to the specific force, does not change between these time points; and proportion of 228 type 2B fibres is comparable to that of the adult animals (Bloemberg \& Quadriatello 2012) already at the age of 21 days. Because young BEH mice were at 26 days of age and BEH+/+ at 37 days, both have already passed the phase where developmental differences might had played a sizable role. However, muscle resistance to exercise-induced protein efflux is 232 dependent on other factors than specific force. Collagen content of extracellular matrix might 233 be of particular importance here. Procollagen processing increases after eccentric exercise in 234 both rats and humans (Han et al. 1999; Crameri et al. 2004). Myostatin belongs to transforming growth factor (TGF- $\beta$ ) family of cytokines that signal through Smad2/3, TAK1p38 MAPK pathways (Lee 2004; Tsukada et al. 2005). Inhibition of TGF- $\beta$ signaling suppresses collagen expression in EDL of mice after injury (Gumucio et al. 2013). It could be that concentration and/or properties of structural proteins become insufficient to sustain high mechanical loads during the phase of rapid muscle growth between 26 and 40 days and 
susceptibility to exercise-induced muscle damage increases in mice with myostatin

dysfunction.

We did not observe any significant difference in loss of peak isometric force between BEH and $\mathrm{BEH}+/+$ muscles during eccentric exercise. Muscle contractions were separated by $10 \mathrm{~s}$ periods of rest that should minimize metabolic inhibition during the exercise (Allen et al. 1995). Our exercise protocol included stretches of similar amplitude, but at half of the velocity compared to the previous study of myostatin effects on muscles of adult (10-12 month old) mice (Mendias et al. 2006). In general, exercise-induced CK efflux from skeletal muscles is not always associated with changes in muscle force. Eccentric contractions often induce an impairment in excitation-contraction coupling of muscle fibers without any clear sign of muscle damage (Warren et al., 1993, Allen, 2001). Such impairment will lead to inactivation of muscles fibers and will protect them from damaging effects of exercise. It appears that changes in force generating capacity can be dissociated from alterations in permeability of sarcolemma and muscle CK efflux during and after exercise. Indeed, the regenerated SOL muscle showed a particularly low exercise-induced CK efflux in spite of relatively modest improvement in fatigue resistance compared to the control muscles

257 (Baltusnikas et al. 2014).

In summary, myostatin dysfunction leads to impairment in muscle force generating capacity of faster contracting EDL and increased susceptibility of both SOL and EDL to protein efflux after eccentric exercise.

\section{ACKNOWLEDGEMENTS}


264 This study was funded by a grant (No. MIP-067/2012) from the Research Council of 265 Lithuania. We are thankful to Petras Jeneckas, Audrius Capskas, and Indre Libnickiene for 266 their technical assistance.

267

268

\section{CONFLICTS OF INTEREST}

269 We declare that we have no conflict of interests.

270

271

\section{REFFERENCES}

272 Allen, D.G., Lännergren, J., and Westerblad, H. 1995. Muscle cell function during prolonged 273 activity: cellular mechanisms of fatigue. Exp. Physiol. 80(4): 497-527.

274 Amelink, G.J., Koot, R.W., Erich, W.B., Van Gijn, J., and Bär, P.R. 1990. Sex-linked 275 variation in creatine kinase release, and its dependence on oestradiol, can be demonstrated in 276 an in vitro rat skeletal muscle preparation. Acta Physiol. Scand. 138(2): 115-24.

277 Amthor, H., Macharia, R., Navarrete, R., Schuelke, M., Brown, S.C., Otto, A., et al. 2007. 278 Lack of myostatin results in excessive muscle growth but impaired force generation. Proc. 279 Natl. Acad. Sci. U.S.A. 104(6): 1835-40.

280 Armstrong, R.B. 1984. Mechanisms of exercise-induced delayed onset muscular soreness: a 281 brief review. Med. Sci. Sports Exerc. 16(6): 529-38.

282 Baltusnikas, J., Kilikevicius, A., Venckunas, T., Fokin, A., Lionikas, A., and Ratkevicius, A. 283 2014. Regenerated soleus muscle shows reduced creatine kinase efflux after contractile 284 activity in vitro. Appl. Physiol. Nutr. Metab. 10: doi:10.1139/apnm-2014-0274.

285 Bogdanovich, S., Krag, T.O., Barton, E.R., Morris, L.D., Whittemore, L.A., Ahima, R.S., et 286 al. 2002. Functional improvement of dystrophic muscle by myostatin blockade. Nature. 287 420(6914): 418-21. 
288 Bloemberg, D., and Quadrilatero J. 2012. Rapid determination of myosin heavy chain 289 expression in rat, mouse, and human skeletal muscle using multicolor immunofluorescence 290 analysis. PLoS One. 7(4):e35273. doi: 10.1371/journal.pone.0035273.

291

Brancaccio, P., Maffulli, N., and Limongelli, F.M. 2007. Creatine kinase monitoring in sport 292 medicine. Br. Med. Bull. 81-82: 209-30.

293

Brooks, S.V., and Faulkner, J.A. 1988. Contractile properties of skeletal muscles from young, 294 adult and aged mice. J. Physiol. 404: 71-82.

Chapman, D.W., Simpson, J.A., Iscoe, S., Robins, T., and Nosaka, K. 2013. Changes in serum fast and slow skeletal troponin I concentration following maximal eccentric contractions. J. Sci. Med. Sport. 16(1): 82-5. doi:10.1016/j.jsams. Jensen, C.H., Koskinen, S., Suetta, S.C., and Kjaer, M. 2004. Enhanced procollagen processing in skeletal muscle after a single bout of eccentric loading in humans. Matrix Biol. 23:259-264.

Han, X.-Y., Wang, W., Komulainen, J., Koskinen, S.O.A., Kovanen, V., Vihko, V., 303 Trackman, P.C., and Takala, T.E.S., 1999. Increased mRNAs for procollagens and key regulating enzymes in rat skeletal muscle following downhill running. Pflugers Arch. 437, $857-864$.

Girgenrath, S., Song, K., and Whittemorem, L.A. 2005. Loss of myostatin expression alters 307 fiber-type distribution and expression of myosin heavy chain isoforms in slow- and fast-type 308 skeletal muscle. Muscle Nerve. 31(1): 34-40.

309 Gokhin, D.S., Ward, S.R., Bremner, S.N., Lieber, R.L. 2008. Quantitative analysis of 310 neonatal skeletal muscle functional improvement in the mouse. J. Exp. Biol. 211(Pt 6):837311 43. doi: 10.1242/jeb.014340. 
312 Grossmann, M. 2014. Myostatin inhibition: a new treatment for androgen deprivation-

313 induced sarcopenia?. J. Clin. Endocrinol. Metab. 99(10): 3625-8. doi:10.1210/jc.2014-3290.

314 Gumucio JP, Flood MD, Phan AC, Brooks SV, Mendias CL. 2013. Targeted inhibition of

315 TGF- $\beta$ results in an initial improvement but long-term deficit in force production after

316 contraction-induced skeletal muscle injury. J.Appl. Physiol. 115: 539-545

317 Jackson, M.J., Wagenmakers, A.J., and Edwards, R.H. 1987. Effect of inhibitors of 318 arachidonic acid metabolism on efflux of intracellular enzymes from skeletal muscle 319 following experimental damage. Biochem. J. 241: 403-407.

320 Kilikevicius, A., Venckunas, T., Zelniene, R., Carroll, A.M., Lionikaite, S., Ratkevicius, A., 321 and Lionikas, A. 2013. Divergent physiological characteristics and responses to endurance 322 training among inbred mouse strains. Scand. J. Med. Sci. Sports, 23(5): 657-68. 323 doi:10.1111/j.1600-0838.2012.01451.

324 Lee, SJ. 2004. Regulation of muscle mass by myostatin. Annu. Rev. Cell. Dev. Biol. 20:61$325 \quad 86$

326 Lionikas, A., Kilikevicius, A., Bunger, L., Meharg, C., Carroll, A.M., Ratkevicius, A., et al. 327 2013. Genetic and genomic analyses of musculoskeletal differences between BEH and BEL 328 strains. Physiol. Genomics. 45(20): 940-7. doi:10.1152/physiolgenomics.00109.2013.

329 Macaluso, F., Isaacs, A.W., and Myburgh, K.H. 2012. Preferential type II muscle fiber 330 damage from plyometric exercise. J. Athl. Train. 47(4): 414-20. doi:10.4085/1062-6050$331 \quad 47.4 .13$.

332 Matsakas, A., Macharia, R., Otto, A., Elashry, M.I., Mouisel, E., Romanello, V., et al. 2012. 333 Exercise training attenuates the hypermuscular phenotype and restores skeletal muscle 334 function in the myostatin null mouse. Exp. Physiol. 97(1): 125-40. 335 doi:10.1113/expphysiol.2011.063008. 
336 Matsakas, A., Mouisel, E., Amthor, H., and Patel, K. 2010. Myostatin knockout mice 337 increase oxidative muscle phenotype as an adaptive response to exercise. J. Muscle Res. Cell. Motil. 31(2): 111-25. doi:10.1007/s10974-010-9214-9.

Matsakas, A., Romanello, V., Sartori, R., Masiero, E., Macharia R, Otto, A., at al. 2013. Food restriction reverses the hyper-muscular phenotype and force generation capacity deficit of the myostatin null mouse. Int. J. Sports. Med. 34(3): 223-31. doi:10.1055/s-0032-1312605.

McHugh, M.P. 2003. Recent advances in the understanding of the repeated bout effect: the protective effect against muscle damage from a single bout of eccentric exercise. Scand. J. Med. Sci. Sports. 13(2): 88-97.

McPherron, A.C., Lawler, A.M., and Lee, S.J. 1997. Regulation of skeletal muscle mass in mice by a new TGF-beta superfamily member. Nature. 387(6628): 83-90. Mendias, C.L., Marcin, J.E., Calerdon, D.R., and Faulkner, J.A. 2006. Contractile properties of EDL and soleus muscles of myostatin-deficient mice. J. Appl. Physiol. 101(3): 898-905.

Pizza, F. X., Koh, T.J., McGregor, S.J., and Brooks, S.V. 2002. Muscle inflammatory cells afterpassive stretches, isometric contractions, and lengthening contractions. J Appl Physiol

Qaisar, R., Renaud, G., Morine, K., Barton, E.R., Sweeney, H.L., and Larsson, L. 2012. Is functional hypertrophy and specific force coupled with the addition of myonuclei at the single muscle fiber level?. FASEB J. 26(3): 1077-85. doi:10.1096/fj.11-192195.

Roy, R.R., Hutchison, D.L., Pierotti, D.J., Hodgson, J.A., and Edgerton, V.R. 1991. EMG 356 patterns of rat ankle extensors and flexors during treadmill locomotion and swimming. J. 357 Appl. Physiol. 70(6): 2522-9.

358 Skurvydas, A., Brazaitis, M., Venckūnas, T., and Kamandulis, S. 2011. Predictive value of 359 strength loss as an indicator of muscle damage across multiple drop jumps. Appl. Physiol. 360 Nutr. Metab. 36(3): 353-60. doi:10.1139/h11-023. 
361 Smith, R.C., and Lin, B.K. 2013. Myostatin inhibitors as therapies for muscle wasting 362 associated with cancer and other disorders. Curr. Opin. Support. Palliat. Care. 7(4): 352-60. 363 doi:10.1097/SPC.

364 Suzuki, K., Totsuka, M., Nakaji, S., Yamada, M., Kudoh, S., Liu, Q., et al. 1999. Endurance 365 exercise causes interaction among stress hormones, cytokines, neutrophil dynamics, and 366 muscle damage. J. Appl. Physiol. 87(4): 1360-7.

367 Tidball, J.G. 1995. Inflammatory cell response to acute muscle injury. Med. Sci. Sports 368 Exerc. 27(7): 1022-32.

369 Tsukada, S., Westwick, J.K., Ikejima K, Sato, N., Rippe, R.A. 2005. SMAD and p38 MAPK 370 signaling pathways independently regulate alphal(I) collagen gene expression in 371 unstimulated and transforming growth factor-beta stimulated hepatic stellate cells. J Biol 372 Chem 280: 10055-10064.

373 Wolfe, R.R. 2006. The underappreciated role of muscle in health and disease. Am. J. Clin. 374 Nutr. 84(3): 475-82.

375 Yu, J.G., Liu, J.X., Carlsson, L., Thornell, L.E., Stål, P.S. Re-evaluation of sarcolemma 376 injury and muscle swelling in human skeletal muscles after eccentric exercise. PLoS One. 3772013 Apr 15;8(4):e62056. doi: 10.1371/journal.pone.0062056. Print 2013.

378 Warren, G.L., Lowe, D.A., Hayes, D.A., Karwoski, C.J., Prior, B.M. and Armstrong, R.B. 379 1993. Excitation failure in eccentric contraction-induced injury of mouse soleus muscle. J. 380 Physiol. 468, 487-99. 
382 Table 1. Age, body mass and muscle mass of soleus (SOL) and extensor digitorum longus 383 (EDL) muscles in $\mathrm{BEH}+/+$ and $\mathrm{BEH}$ mice with the wild type and dysfuctional myostatin, 384 respectively. Values are means and S.D.

\begin{tabular}{|l|c|c|c|c|c|}
\hline \multirow{2}{*}{} & \multicolumn{2}{|c|}{ SOL } & \multicolumn{2}{c|}{ EDL } \\
\cline { 2 - 6 } & BEH+/+ & BEH & BEH+/+ & BEH & BEH (Older) \\
& $(\mathrm{n}=25)$ & $(\mathrm{n}=22)$ & $(\mathrm{n}=15)$ & $(\mathrm{n}=15)$ & $(\mathrm{n}=11)$ \\
\hline Age & $36.5 \pm 5.5$ & $31.7 \pm 0.4$ & $36.9 \pm 2.7$ & $26.2 \pm 1.2$ & $38.5 \pm 1.7$ \\
\hline (days) & & & & & \\
\hline mody & $26.8 \pm 2.6$ & $22.9 \pm 3.0$ & $27.1 \pm 1.8$ & $16.3 \pm 1.3$ & $31.4 \pm 1.5$ \\
\hline Muscle & $5.7 \pm 0.5$ & $6.0 \pm 0.6$ & $7.8 \pm 0.4$ & $7.8 \pm 0.9$ & $13.8 \pm 0.9$ \\
mass (mg) & & & & & \\
\hline
\end{tabular}


387 Table 2. Muscle properties of $\mathrm{BEH}+/+$ and $\mathrm{BEH}$ mice with the wild type and dysfuctional 388 myostatin, respectively. SOL is soleus muscle; EDL is extensor digitorum longus (EDL). $\mathrm{L}_{0}$ 389 is optimal muscle length. pCSA is physiological cross-sectional area. Values are means and 390 S.D. ** $\mathrm{P}<0.01 \mathrm{BEH}+/+$ vs $\mathrm{BEH}, \# \# \mathrm{P}<0.01 \mathrm{BEH}$ vs $\mathrm{BEH}$ (Older).

\begin{tabular}{|c|c|c|c|c|c|}
\hline & \multicolumn{2}{|c|}{ SOL } & \multicolumn{3}{|c|}{ EDL } \\
\hline & $\mathrm{BEH}+/+$ & $\mathrm{BEH}$ & $\mathrm{BEH}+/+$ & $\mathrm{BEH}$ & BEH (Older) \\
\hline $\mathrm{L}_{0}(\mathrm{~mm})$ & $12.4 \pm 0.9$ & $12.5 \pm 0.5$ & $14.3 \pm 0.6$ & $\begin{array}{c}12.0 \pm 0.5 \\
* *\end{array}$ & $\begin{array}{c}13.0 \pm 0.6 \\
* *\end{array}$ \\
\hline $\begin{array}{l}\mathrm{pCSA} \\
\left(\mathrm{mm}^{2}\right)\end{array}$ & $0.84 \pm 0.06$ & $0.92 \pm 0.08$ & $1.18 \pm 0.11$ & $1.40 \pm 0.11 * *$ & $\begin{array}{c}2.15 \pm 0.15 \\
* *, \# \#\end{array}$ \\
\hline $\begin{array}{l}\text { Peak } \\
\text { isometric } \\
\text { force } \\
(\mathrm{mN})\end{array}$ & $173.8 \pm 17.6$ & $180.5 \pm 13.7$ & $160.3 \pm 23.6$ & $\begin{array}{c}145.1 \pm 10.5 \\
* *\end{array}$ & $\begin{array}{c}219.9 \pm 25.4 \\
* *, \# \#\end{array}$ \\
\hline $\begin{array}{l}\text { Specific } \\
\text { force } \\
\left(\mathrm{mN} / \mathrm{mm}^{2}\right)\end{array}$ & $273.8 \pm 33.3$ & $271.0 \pm 35.2$ & $137.1 \pm 23.2$ & $\begin{array}{c}104.3 \pm 12.1 \\
*\end{array}$ & $\begin{array}{c}102.3 \pm 9.8 \\
* *\end{array}$ \\
\hline
\end{tabular}


393 Table 3. Twitch and tetanus contraction and relaxation times in skeletal muscles of $\mathrm{BEH}+/+$ 394 and BEH mice, respectively. SOL is soleus muscle; EDL is extensor digitorum longus (EDL). 395 Values are means and S.D.; * $\mathrm{P}<0.05,{ }^{*} * \mathrm{P}<0.01 \mathrm{BEH}$ vs $\mathrm{BEH}+/+, \# \mathrm{P}<0.05, \# \# \mathrm{P}<0.01$ 396 BEH (Older) vs BEH.

\begin{tabular}{|c|c|c|c|c|c|}
\hline & & & & EDL & \\
\hline & $\mathrm{BEH}+/+$ & $\mathrm{BEH}$ & $\mathrm{BEH}+/+$ & $\mathrm{BEH}$ & BEH (Older) \\
\hline $\begin{array}{l}\text { Twitch } \\
\text { contraction } \\
\text { time (ms) }\end{array}$ & $69.5 \pm 8.1$ & $\begin{array}{c}56.9 \pm 9.1 \\
* *\end{array}$ & $21.6 \pm 0.7$ & $\begin{array}{c}28.3 \pm 1.3 \\
* *\end{array}$ & $\begin{array}{c}25.2 \pm 1.6 \\
* *, \#\end{array}$ \\
\hline $\begin{array}{l}\text { Twitch } \\
\text { relaxation } \\
\text { time }(\mathrm{ms})\end{array}$ & $313.9 \pm 144.2$ & $304.4 \pm 91.5$ & $120.6 \pm 23.5$ & $\begin{array}{c}96.2 \pm 6.4 \\
*\end{array}$ & $\begin{array}{l}86.2 \pm 8.4 \\
*\end{array}$ \\
\hline $\begin{array}{l}\text { Tetanus } \\
\text { contraction } \\
\text { time (ms) }\end{array}$ & $573.8 \pm 54.6$ & $\begin{array}{c}473.0 \pm 72.8 \\
* *\end{array}$ & $132.6 \pm 9.8$ & $143.0 \pm 6.0$ & $\begin{array}{c}125.6 \pm 5.7 \\
* *, \# \#\end{array}$ \\
\hline $\begin{array}{l}\text { Tetanus } \\
\text { relaxation } \\
\text { time (ms) }\end{array}$ & $200.7 \pm 18.2$ & $\begin{array}{c}163.2 \pm 30.7 \\
* *\end{array}$ & $58.7 \pm 2.4$ & $\begin{array}{c}68.6 \pm 2.4 \\
* *\end{array}$ & $\begin{array}{c}68.4 \pm 3.9 \\
* *\end{array}$ \\
\hline
\end{tabular}




\section{FIGURE CAPTIONS}

400 Figure 1. Peak isometric force for soleus (A) and extensor digitorum longus (B) muscles of $401 \mathrm{BEH}+/+$ and $\mathrm{BEH}$ mice with the wild type and mutant myostatin, respectively, during 100 402 contractions repeated every $10 \mathrm{~s}$. The data for older BEH mice with the mutant myostatin, $403 \mathrm{BEH}$ (Older), is also shown. * $\mathrm{P}<0.05$ for $\mathrm{BEH}+/+$ vs $\mathrm{BEH}($ Older); \# $\mathrm{P}<0.05, \# \# \mathrm{P}<0.01$ 404 for BEH vs BEH (Older), respectively. Values are means with S.D.

405

406 Figure 2. The total CK efflux at rest and after eccentric exercise from soleus (SOL, A) and 407 extensor digitorum longus (EDL, B) muscles of $\mathrm{BEH}$ and $\mathrm{BEH}+/+$ mice with the mutant and 408 wild type myostatin, respectively. The data for older BEH mice with mutant myostatin, BEH 409 (Older), is also shown (B). * $\mathrm{P}<0.05, * * * \mathrm{P}<0.001$ for $\mathrm{BEH}+/+$ vs $\mathrm{BEH}$; \# $\mathrm{P}<0.001$ for 410 BEH vs BEH (Older) mice. Values are means with S.D. 
A)

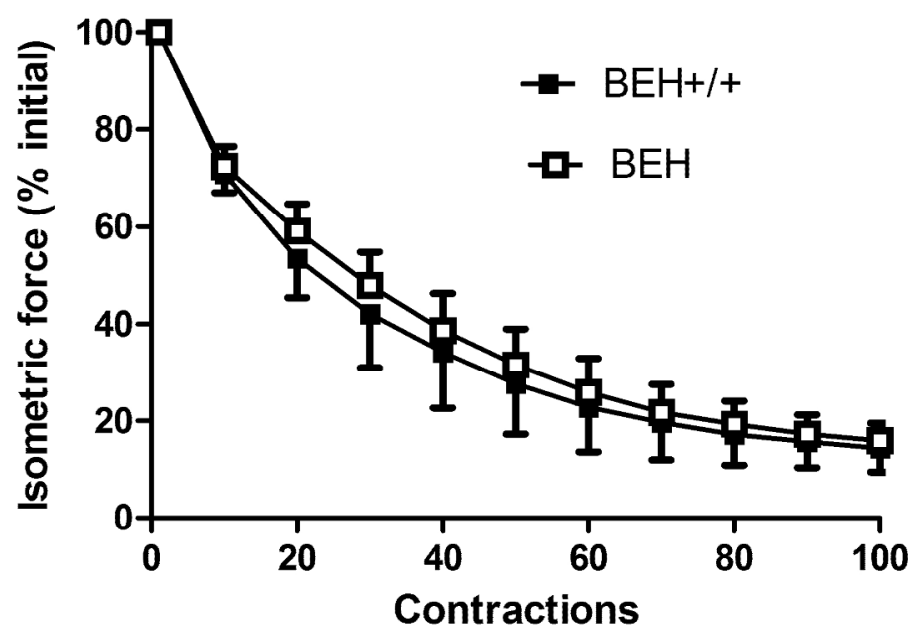

B)

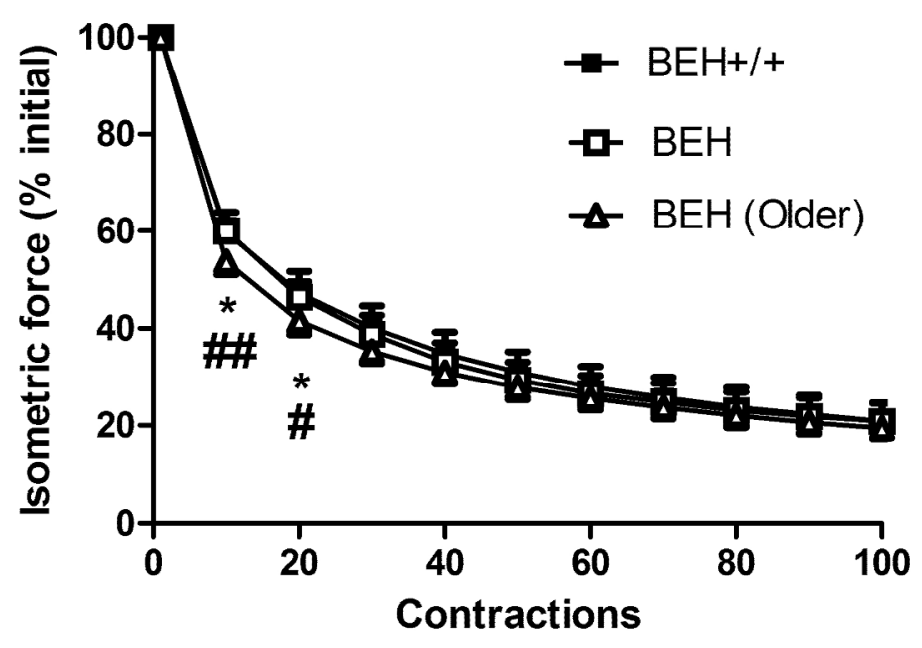

Figure 1. Peak isometric force for soleus $(A)$ and extensor digitorum longus $(B)$ muscles of $B E H+/+$ and $B E H$ mice with the wild type and mutant myostatin, respectively, during 100 contractions repeated every $10 \mathrm{~s}$. The data for older BEH mice with the mutant myostatin, $\mathrm{BEH}$ (Older), is also shown. * $\mathrm{P}<0.05$ for $\mathrm{BEH}+/+$ vs BEH (Older); \# P < 0.05, \#\# P < 0.01 for BEH vs BEH (Older), respectively. Values are means with S.D. $181 \times 267 \mathrm{~mm}$ (300 x $300 \mathrm{DPI})$ 


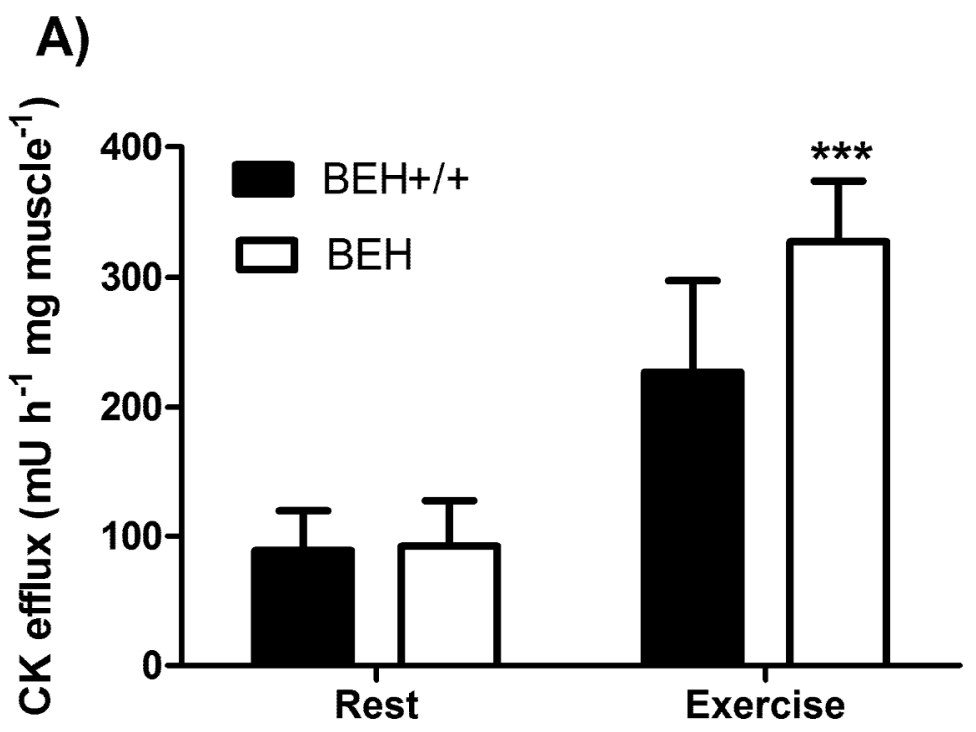

B)

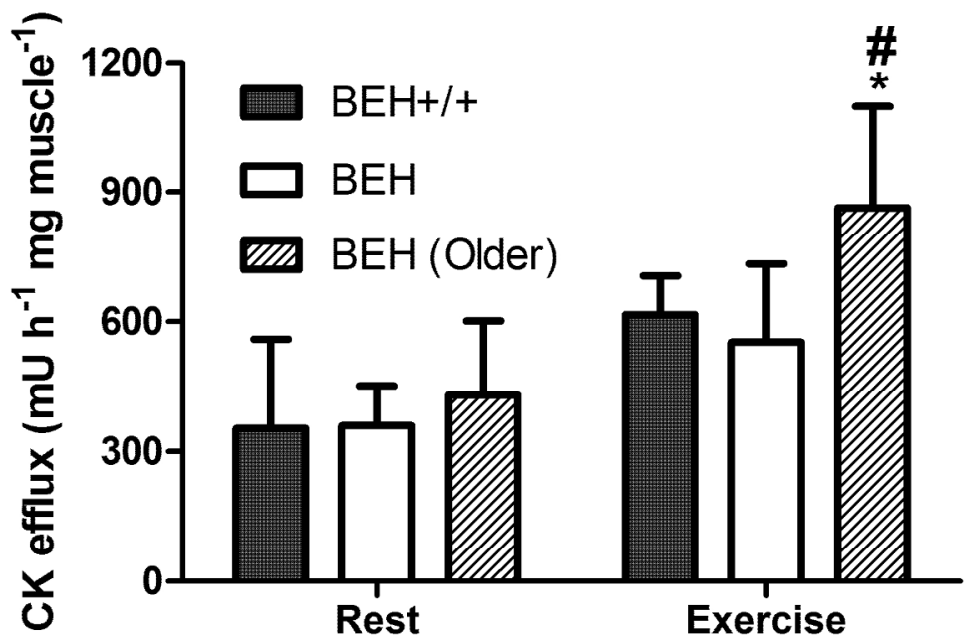

Figure 2. The total CK efflux at rest and after eccentric exercise from soleus (SOL, A) and extensor digitorum longus (EDL, B) muscles of $\mathrm{BEH}$ and $\mathrm{BEH}+/+$ mice with the mutant and wild type myostatin, respectively. The data for older $\mathrm{BEH}$ mice with mutant myostatin, $\mathrm{BEH}$ (Older), is also shown (B). * $\mathrm{P}<$ 0.05 , *** $\mathrm{P}<0.001$ for $\mathrm{BEH}+/+$ vs $\mathrm{BEH}$; \# $\mathrm{P}<0.001$ for $\mathrm{BEH}$ vs $\mathrm{BEH}$ (Older) mice. Values are means with S.D.

$180 \times 242 \mathrm{~mm}(300 \times 300 \mathrm{DPI})$ 